\title{
PENERAPAN LOGIKA FUZZY METODE SUGENO UNTUK MENENTUKAN JUMLAH PRODUKSI ROTI BERDASARKAN DATA PERSEDIAAN DAN JUMLAH PERMINTAAN (STUDI KASUS: PABRIK ROTI SARINDA AMBON)
}

\author{
Dorteus Lodewyik Rahakbauw \\ Jurusan Matematika FMIPA Universitas Pattimura \\ Jl. Ir. M. Putuhena, Kampus Unpatti, Poka-Ambon, Maluku \\ e-mail: lodewyik@gmail.com
}

\begin{abstract}
Abstrak
Keuntungan yang maksimal diperoleh dari penjualan yang maksimal. Apabila jumlah produk yang diproduksi oleh perusahaan kurang dari jumlah permintaan maka perusahaan akan kehilangan peluang untuk mendapatkan keuntungan yang maksimal dan sebaliknya. Oleh karena itu, perencanaan jumlah produk dalam Pabrik Roti Sarinda sangatlah penting. Agar dapat memenuhi permintaan pasar dengan tepat dan dengan jumlah yang sesuai. Faktor-faktor yang perlu diperhatikan dalam menentukan jumlah produk, antara lain: jumlah persediaan dan jumlah permintaan. Penulisan dan pembahasan pada penelitian ini adalah tentang sistem inferensi Fuzzy Metode Sugeno, penerapan sistem inferensi Fuzzy Metode Sugeno untuk menentukan jumlah produksi berdasarkan jumlah permintaaan dan data persediaan yang dimana data dari penulisan ini didapat dari Pabrik Roti Sarinda dengan menggunakan Matlab. Untuk membuat rancangan program yang bisa diharapkan dapat diaplikasikan dan dipakai, sehingga membantu proses penentuan jumlah produksi berdasarkan data persediaan dan jumlah permintaaan pada Pabrik Roti Sarinda. Logika Fuzzy Metode Sugeno dalam menentukan jumlah produksi roti berdasarkan data persediaan dan jumlah permintaan yang telah dibangun dapat digunakan untuk membantu perusahaan dalam mengambil sebuah keputusan dengan nilai kebenaran mencapai $86.92165 \%$.
\end{abstract}

Kata Kunci: Logika Fuzzy, permintaan, persediaan, produksi.

\section{APPLICATION OF FUZZY LOGIC METHOD SUGENO TO DETERMINE THE TOTAL PRODUCTION OF BREAD, BASED ON SUPPLIES AND TOTAL DEMAND DATA (CASE STUDY: BREAD FACTORY SARINDA AMBON)}

\begin{abstract}
The maximum benefit is obtained from the maximum sales. If the number of products manufactured by the company is less than the demand, then the company will lose the opportunity to gain the maximum profit and vice versa. Therefore, planning the number of products in the Bread Factory Sarinda very important. In order to meet market demand appropriately and by a corresponding amount. Factors to consider in determining the amount of the product, among other things: the amount of supply and demand. Writing and discussion in this study is about the inference system Fuzzy Sugeno method, application of the inference system Fuzzy Sugeno method to determine the amount of production based on the number of request and inventory data where the data of this paper obtained from the Bread Factory Sarinda and processed using Matlab. To making a program that can be expected to be applied and used, thus helping the process of determining the amount of production based on inventory data and the number of request at the Bread Factory Sarinda Sugeno Fuzzy Logic method in determining the amount of bread production based on inventory data and the number of requests that have been built can be used to assist companies in taking a decision with the truth value reaching $86.92165 \%$.
\end{abstract}

Keywords: Demand, fuzzy logic, production, supply. 


\section{Pendahuluan}

Pada era globalisasi saat ini persaingan pasar dalam dunia industri sangat kompetitif sehingga dibutuhkan kemampuan pengelola perusahaan yang profesional agar dapat memenangkan persaingan dalam pasar global. Pada bidang produksi kemampuan itu antara lain adalah kemampuan merencanakan atau menentukan jumlah produksi barang. Hal ini agar dapat memenuhi permintaan pasar dengan jumlah yang sesuai dengan memperhatikan persediaan barang sehingga bisa mendapatkan keuntungan yang maksimal.

Keuntungan yang maksimal diperoleh dari penjualan yang maksimal. Dimana penjualan yang maksimal artinya dapat memenuhi semua permintaan yang ada, apa bila jumlah produk yang di produksi oleh perusahan kurang dari permintaan maka perusahan akan kehilangan peluang untuk mendapatkan keuntungan yang maksimal. Sebaliknya apabila perusahan memproduksi produk lebih banyak dari jumlah permintaan maka perusahan akan mengalami kerugian. Oleh karena itu, perencanaan jumlah produksi dalam suatu perusahaan sangatlah penting agar dapat memenuhi permintaan pasar yang tepat dan dengan jumlah yang sesuai. Faktor-faktor yang perlu diperhatikan dalam menentukan jumlah produksi, antara lain: jumlah persediaan dan jumlah permintaan.

Logika Fuzzy merupakan ilmu yang mempelajari mengenai ketidakpastian. Logika Fuzzy juga mampu untuk memetakan suatu ruang input kedalam suatu ruang output dengan tepat. Dalam teori sistem Fuzzy dikenal suatu konsep sistem Fuzzy yang digunakan dalam proses prediksi pada umumnya terdiri atas empat tahap, yaitu fuzzifikasi (proses pengubahan bilangan tegas kedalam bentuk bilangan Fuzzy), pembentukan rule basis (basis aturan Fuzzy), sistem inferensi atau penalaran Fuzzy, defuzzifikasi (proses pengubahan bilangan Fuzzy hasil dari sistem inferensi Fuzzy ke dalam bilangan tegas). Salah satu metode dalam sistem Fuzzy yang dapat dipakai dalam memprediksi adalah metode Sugeno, metode ini hampir sama dengan metode Mamdani hanya saja output (konsekuen) bukan merupakan himpunan Fuzzy tetapi berupa konstanta atau persamaan linier.

Dengan adanya masalah tersebut maka untuk menentukan jumlah produksi dalam memenuhi permintaan konsumen yang fluktuatif diperlukan suatu alternatif pemecahan masalah tanpa menambah fasilitas yang ada, yaitu dengan mengaplikasikan Metode Fuzzy Sugeno mengunakan tool box Matlab. Penerapan Metode Fuzzy Sugeno menggunakan tool box Matlab dalam perencanaan jumlah produksi, diharapkan perusahaan dapat mengatasi fluktuasi permintaan konsumen dengan biaya produksi yang minimal. Maka, pada penelitian ini akan diterapkan Logika Fuzzy Metode Sugeno untuk menentukan jumlah produksi barang berdasarkan data persediaan dan jumlah permintaan pada Pabrik Roti Sarinda.

\section{Tinjauan Pustaka}

\subsection{Logika Fuzzy}

Konsep tentang logika Fuzzy diperkenalkan oleh Prof. Lotfi Astor Zadeh pada 1962. Logika Fuzzy adalah metodologi sistem kontrol pemecahan masalah, yang cocok untuk diimplementasikan pada sistem, mulai dari sistem yang sederhana, sistem kecil, embedded system, jaringan PC, multichannel atau workstation berbasis akuisisi data, dan sistem kontrol. Metodologi ini dapat diterapkan pada perangkat keras, perangkat lunak, atau kombinasi keduanya. Dalam logika klasik dinyatakan bahwa segala sesuatu bersifat biner, yang artinya adalah hanya mempunyai dua kemungkinan, "Ya atau Tidak", "Benar atau Salah", "Baik atau Buruk", dan lain-lain. Oleh karena itu, semua ini dapat mempunyai nilai keanggotaan 0 atau 1. Akan tetapi, dalam logika Fuzzy kemungkinan nilai keanggotaan berada diantara 0 dan 1. Artinya,bisa saja suatu keadaan mempunyai dua nilai "Ya dan Tidak", "Benar dan Salah", "Baik dan Buruk" secara bersamaan, namun besar nilainya tergantung pada bobot keanggotaan yang dimilikinya.

\subsection{Konsep Dasar Himpunan Fuzzy}

Jika $X$ adalah sebuah koleksi obyek-obyek yang dinotasikan dengan $x$, maka himpunan Fuzzy $\grave{A}$ dalam $X$ adalah sebuah himpunan pasangan berurutan $\grave{A}=\left\{x, \mu_{\grave{A}} \mid(x) \in X\right\}$. Notasi $\mu_{\grave{A}}(x)$ disebut fungsi keanggotaan atau derajat keanggotaan $x$ dalam $A$ yang memetakan $X$ ke ruang keanggotaan $M$ yang terletak pada rentang $[0,1]$, bila $\mathrm{M}$ hanya memuat dua titik 0 dan 1 , maka $\mathrm{A}$ adalah bukan Fuzzy dan $\mu_{\grave{A}}(x)$ serupa dengan karakteristik fungsi himpunan non Fuzzy. [1] 


\subsection{Penalaran Fuzzy Metode Sugeno}

Penalaran dengan metode Sugeno hampir sama dengan penalaran Mamdani, hanya saja output (konsekuen) sistem tidak berupa himpunan Fuzzy, melainkan berupa konstanta atau persamaan linear. Michio Sugeno mengusulkan penggunaan singleton sebagai fungsi keanggotaan dari konsekuen. Singleton adalah sebuah himpunan Fuzzy dengan fungsi keanggotaan yang pada titik tertentu mempunyai sebuah nilai dan 0 di luar titik tersebut. Ada 2 model Fuzzy metode Sugeno yaitu sebagai berikut:

a. Model Fuzzy Sugeno Orde-Nol

Secara umum bentuk model Fuzzy Sugeno Orde Nol adalah:

IF $\left(x_{1}\right.$ is $\left.A_{1}\right) \circ\left(x_{2}\right.$ is $\left.A_{2}\right) \circ\left(x_{3}\right.$ is $\left.A_{3}\right) \circ \ldots \circ\left(x_{N}\right.$ is $\left.A_{N}\right)$ THEN $z=k$ dengan $A_{i}$ adalah himpunan Fuzzy ke- $i$ sebagai antesenden, dan $k$ adalah suatu konstanta sebagai konsekuen.

b. Model Fuzzy Sugeno Orde-Satu

Secara umum bentuk model Fuzzy Sugeno Orde-Satu adalah:

$\mathrm{IF}\left(x_{1}\right.$ is $\left.A_{1}\right) \circ\left(x_{2}\right.$ is $\left.A_{2}\right) \circ\left(x_{3}\right.$ is $\left.A_{3}\right) \circ \ldots \circ\left(x_{N}\right.$ is $\left.A_{N}\right)$ THEN $z=p_{1} * x_{1}+\cdots+p_{N} * x_{N}+q$ dengan $\mathrm{A}_{i}$ adalah himpunan Fuzzy ke- $i$ sebagai antesenden, dan $\mathrm{p}_{i}$ adalah suatu konstanta ke- $i$ dan $q$ juga merupakan konstanta dalam konsekuen.

Berdasarkan model Fuzzy tersebut, ada tahapan-tahapan yang harus dilakukan dalam implementasi metode Sugeno yaitu sebagai berikut:

1) Pembentukan himpunan Fuzzy

Pada tahapan ini variabel input dari system Fuzzy ditransfer ke dalam himpunan Fuzzy untuk dapat digunakan dalam perhitungan nilai kebenaran dari premis pada setiap aturan dalam basis pengetahuan. Dengan demikian tahap ini mengambil nilai-nilai tegas dan menentukan derajat di mana nilai-nilai tersebut menjadi anggota dari setiap himpunan Fuzzy yang sesuai.

2) Aplikasi fungsi implikasi

Tiap-tiap aturan (proposisi) pada basis pengetahuan Fuzzy akan berhubungan dengan suatu relasi Fuzzy. Bentuk umum dari aturan yang digunakan dalam fungsi implikasi adalah sebagai berikut: IF $x$ is $A$ THEN $y$ is $B$ dengan $x$ dan $y$ adalah skalar, dan $A$ dan $B$ adalah himpunan Fuzzy. Proposisi yang mengikuti IF disebut sebagai antesenden sedangkan proposisi yang mengikuti THEN disebut konsekuen. Proposisi ini dapat diperluas dengan menggunakan operator Fuzzy seperti, IF $\left(x_{1}\right.$ is $\left.A_{1}\right) \circ\left(x_{2}\right.$ is $\left.A_{2}\right) \circ\left(x_{3}\right.$ is $\left.A_{3}\right) \circ \ldots \circ\left(x_{N}\right.$ is $\left.A_{N}\right)$ THEN $y$ is $B$ dengan $\circ$ adalah operator (misal: OR atau AND). Secara umum fungsi implikasi yang dapat digunakan yaitu sebagai berikut:

- Min (minimum) Fungsi ini akan memotong output himpunan Fuzzy.

- Dot (product) Fungsi ini akan menskala output himpunan Fuzzy.

Pada metode Sugeno ini, fungsi implikasi yang digunakan adalah fungsi min.

c. Defuzzifikasi ( Defuzzification ) Input dari proses defuzzifikasi adalah himpunan Fuzzy yang dihasilkan dari proses komposisi dan output adalah sebuah nilai. Untuk aturan IFTHEN Fuzzy dalam persamaan $R U(\mathrm{k})=\mathrm{IF} \mathrm{x} x_{1}$ is $A_{1 k}$ and $\ldots$ and $\mathrm{x}_{n}$ is $A_{n k}$ THEN $y$ is $B_{k}$, dimana $A_{1 k}$ dan $B_{k}$ berturut-turut adalah himpunan Fuzzy dalam $U_{i} R$ ( $U$ dan $V$ adalah domain fisik), $i=1,2, \ldots, n$ dan $x=\left(x_{1}, x_{2}, \ldots, x_{n}\right) U$ dan $y V$ berturut-turut adalah variabel input dan output (linguistik) dari sistem Fuzzy. Defuzzifier pada persamaan di atas didefinisikan sebagai suatu pemetaan dari himpunan Fuzzy $B$ ke dalam $V R$ (yang merupakan output dari inferensi Fuzzy) ke titik tegas $y * V$. [2]. Pada metode Sugeno defuzzification dilakukan dengan perhitungan Weight Average (WA):

Keterangan:

$$
W A=\frac{\alpha_{1 z_{1}}+\alpha_{2} z_{2}+\alpha_{3} z_{3}+\cdots+\alpha_{n} z_{n}}{\alpha_{1}+\alpha_{2}+\alpha_{3}+\cdots+\alpha_{n}}
$$

$W A=$ Nilai rata-rata, $\alpha_{n}=$ nilai predikat aturan ke- $n$, dan $z_{n}=$ indeks nilai output (konstanta) ke- $n$.

\subsection{Fungsi Keanggotaan}

Fungsi keanggotaan adalah grafik yang mewakili besar dari derajat keanggotaan masing-masing variabel input yang berada dalam interval antara 0 dan 1 . Derajat keanggotaan sebuah variabel $x$ dilambangkan dengan simbol $\mu(x)$. Aturan-aturan (Rules) menggunakan nilai keanggotaan sebagai faktor bobot untuk menentukan pengaruhnya pada saat melakukan inferensi dalam menarik kesimpulan. Ada 
beberapa fungsi yang bisa digunakan namun dalam penelitian ini peneliti memakai fungsi keangotaan kurva bahu dan kurva segitiga.

\section{a. Representasi Kurva Bahu}

Fungsi keanggotaan yang merepresentasikan kurva bahu kiri:

$$
\mu(x)= \begin{cases}0, & x \leq a ; \\ \frac{b-x}{b-a}, & a \leq x \leq b ; \\ 1, & x \geq b .\end{cases}
$$

Fungsi keanggotaan yang merepresentasikan kurva bahu kanan:

$$
\mu(x)= \begin{cases}0, & x \leq b ; \\ \frac{x-b}{c-b}, & b \leq x \leq c ; \\ 1, & x \geq c .\end{cases}
$$

\section{b. Representasi kurva segitiga}

Fungsi keanggotaan yang merepresentasikan kurva segitiga adalah

$$
\mu(x)= \begin{cases}0, & x \leq a \text { atau } x \geq c ; \\ \frac{x-a}{b-a}, & a<x<b ; \\ \frac{c-x}{c-b}, & b<x<c .\end{cases}
$$

\section{Keterangan :}

$a=$ nilai domain terkecil yang mempunyai derajat keanggotaan nol;

$b=$ nilai domain yang mempunyai derajat keanggotaan satu;

$c=$ nilai domain terbesar yang mempunyai derajat keanggotaan nol;

$x=$ nilai input atau output yang akan diubah ke dalam bilangan Fuzzy.

Fungsi untuk memetakan kembali nilai Fuzzy menjadi nilai crisp yang menjadi output/nilai solusi permasalahan.

\subsection{Galat Presentasi}

Dalam banyak situasi peramalan, ketepatan dipandang sebagai kriteria penolakan untuk memilih suatu peramalan. Galat persentase merupakan suatu ukuran ketepatan peramalan, dalam penelitian ini peneliti memakai nilai tengah galat persen atau MPE (Mean Percentage Error) bentuk persamaannya seperti berikut.

$$
\mathrm{MPE}=\frac{\sum_{t=1}^{n} \frac{\left(Y_{t}-\hat{Y}_{t}\right)}{Y_{t}} \times 100 \%}{n}
$$

\section{Hasil dan Pembahasan}

\subsection{Data}

Bahan penelitian yang dipakai berupa data sekunder yang hanya terdiri dari data persediaan minimal (600 bks) maksimal (900 bks), jumlah permintaan minimal (1000 bks) maksimal (1600 bks), dan jumlah produksi minimal (1950 bks) maksimal (2600) dalam satu hari. Dengan data-data tersebut, kemudian peneliti menggunakan Microsoft Excel 2010 untuk memanggil data secara random untuk mendapatkan data 
persediaan, permintaan, dan produksi perhari dalam jangka waktu satu bulan, untuk bulan Januari 2016 dapat dilihat pada Tabel berikut.

Tabel 1. Data Permintaan, Persediaan dan Produksi

\begin{tabular}{|c|c|c|c|c|}
\hline Tgl & Nama Roti & Prm & Prs & Prd \\
\hline $02 / 01 / 2016$ & Roti Kaya & 1415 & 622 & 2400 \\
\hline $04 / 01 / 2016$ & Roti Kaya & 1145 & 865 & 2210 \\
\hline $05 / 01 / 2016$ & Roti Kaya & 1264 & 783 & 2118 \\
\hline $06 / 01 / 2016$ & Roti Kaya & 1295 & 736 & 2098 \\
\hline $07 / 01 / 2016$ & Roti Kaya & 1324 & 854 & 2565 \\
\hline $08 / 01 / 2016$ & Roti Kaya & 1589 & 806 & 2579 \\
\hline $09 / 01 / 2016$ & Roti Kaya & 1279 & 679 & 2282 \\
\hline $11 / 01 / 2016$ & Roti Kaya & 1239 & 873 & 2339 \\
\hline $12 / 01 / 2016$ & Roti Kaya & 1398 & 877 & 2541 \\
\hline $13 / 01 / 2016$ & Roti Kaya & 1090 & 888 & 1996 \\
\hline $14 / 01 / 2016$ & Roti Kaya & 1064 & 894 & 2167 \\
\hline $15 / 01 / 2016$ & Roti Kaya & 1384 & 722 & 2362 \\
\hline $16 / 01 / 2016$ & Roti Kaya & 1315 & 766 & 2417 \\
\hline $18 / 01 / 2016$ & Roti Kaya & 1355 & 607 & 2341 \\
\hline $19 / 01 / 2016$ & Roti Kaya & 1156 & 730 & 2218 \\
\hline $20 / 01 / 2016$ & Roti Kaya & 1241 & 680 & 2309 \\
\hline $21 / 01 / 2016$ & Roti Kaya & 1570 & 653 & 2437 \\
\hline $22 / 01 / 2016$ & Roti Kaya & 1297 & 629 & 2229 \\
\hline $23 / 01 / 2016$ & Roti Kaya & 1366 & 697 & 2373 \\
\hline $25 / 01 / 2016$ & Roti Kaya & 1185 & 728 & 2208 \\
\hline $26 / 01 / 2016$ & Roti Kaya & 1089 & 736 & 2093 \\
\hline $27 / 01 / 2016$ & Roti Kaya & 1519 & 618 & 2258 \\
\hline $28 / 01 / 2016$ & Roti Kaya & 1030 & 616 & 2157 \\
\hline $29 / 01 / 2016$ & Roti Kaya & 1376 & 662 & 2301 \\
\hline $30 / 01 / 2016$ & Roti Kava & 1555 & 863 & 2488 \\
\hline
\end{tabular}

\subsection{Proses Perhitungan Logika Fuzzy Metode Sugeno}

\section{a. Pembentukan Himpunan Fuzzy (fuzzifikasi)}

Pada metode Fuzzy sugeno, baik variabel input maupun output dibagi menjadi satu atau lebih himpunan Fuzzy. Dalam penentuan jumlah produksi barang berdasarkan data persediaan dan jumlah permintaan, variabel input dibagi menjadi dua yaitu variabel persediaan dan permintaan sedangkan yang menjadi variabel output adalah jumlah produksi produksi. Penentuan variabel yang digunakan dalam penelitian ini, terlihat pada Tabel 2.

Tabel 2. Semesta pembicaraan untuk semua variabel Fuzzy

\begin{tabular}{|c|c|c|}
\hline \multirow{2}{*}{ Fungsi } & Nama Variabel & Semesta Pembicaraan \\
\hline \multirow{2}{*}{ Input } & Permintaan & {$[1000-1600]$} \\
\cline { 2 - 3 } & Persediaan & {$[600-900]$} \\
\hline \multirow{2}{*}{ Output } & Jumlah Produksi & {$[1950-2600]$} \\
\hline
\end{tabular}

Dari tabel di atas yang menjadi semesta pembicaraan adalah data permintaan minimal dan maksimal, persediaan minimal dan maksimal, dan produksi minimal dan maksimal dalam satu hari, sedangkan yang akan menjadi domain untuk komposisi aturan Fuzzy adalah data random yang telah dibuat pada Tabel.1 Berdasarkan data tersebut dilihat kembali nilai minimal dan maksimal dari variabel input maupun variabel output seperti terlihat pada Tabel 3. 
Tabel 3. Nilai Minimal dan Maksimal dari Variabel Input Output Pada Data Random

\begin{tabular}{|c|c|c|}
\hline Fungsi & Nama Variabel & Domain \\
\hline \multirow{2}{*}{ Input } & Permintaan & {$[1030-1589]$} \\
\cline { 2 - 3 } & Persediaan & {$[607-894]$} \\
\hline Output & Jumlah Produksi & {$[1996-2579]$} \\
\hline
\end{tabular}

\section{b. Pembentukan Fuzzy Rule}

Pada tahap ini, nilai keanggotaan himpunan permintaan dan persediaan saat ini dicari menggunakan fungsi keanggotaan himpunan Fuzzy berdasarkan data. Pembentukan Aturan Fuzzy, Dari dua variabel input dan sebuah variabel output yang telah didefinisikan, dengan melakukan analisa data terhadap batas tiap-tiap himpunan Fuzzy pada tiap-tiap variabelnya maka terdapat 9 aturan Fuzzy yang akan dipakai dalam sistem ini, dengan susunan aturan IF permintaan IS ... AND persediaan IS ... THEN produksi IS ..., hasilnya dapat dilihat pada Tabel 4, yaitu:

Tabel. 4 Aturan Fuzzy

\begin{tabular}{|c|c|c|c|}
\hline \multirow{2}{*}{ No } & \multicolumn{3}{|c|}{ Variabel } \\
\cline { 2 - 4 } & \multicolumn{2}{|c|}{ Input } & Output \\
\cline { 2 - 4 } & Permintaan & Persediaan & Produksi \\
\hline 1 & Kecil & Sedikit & Sedikit \\
\hline 2 & Kecil & Sedang & Sedikit \\
\hline 3 & Kecil & Banyak & Sedikit \\
\hline 4 & Sedang & Sedikit & Sedikit \\
\hline 5 & Sedang & Sedang & Sedang \\
\hline 6 & Sedang & Banyak & Sedang \\
\hline 7 & Besar & Sedikit & Sedikit \\
\hline 8 & Besar & Sedang & Sedang \\
\hline 9 & Besar & Banyak & Banyak \\
\hline
\end{tabular}

Berikut adalah cara untuk mendapatkan nilai keanggotan berdasarkan variabel linguistik dan variabel numerik yang digunakan:

- Fungsi keanggotaan himpunan Fuzzy KECIL, SEDANG, dan BESAR dari variabel Permintaan

$$
\begin{aligned}
& \mu[x] \text { KECIL }= \begin{cases}1, & x \leq 1030 \\
\frac{1310-x}{1310-1030}, & 1030 \leq x \leq 1310 ; \\
0, & x \geq 1310 .\end{cases} \\
& \mu[x] \text { SEDANG }= \begin{cases}0, & x \leq 1030 \text { atau } x \geq 1589 \\
\frac{x-1310}{1310-1030}, & 1030 \leq x \leq 1310 \\
\frac{1589-x}{1589-1310}, & 1310 \leq x \leq 1589 .\end{cases} \\
& \mu[x] \text { BESAR }= \begin{cases}0, & x \leq 1310 \\
\frac{x-1310}{1589-1310} ; & 1310 \leq x \leq 1589 \\
1, & x \geq 1589 .\end{cases}
\end{aligned}
$$




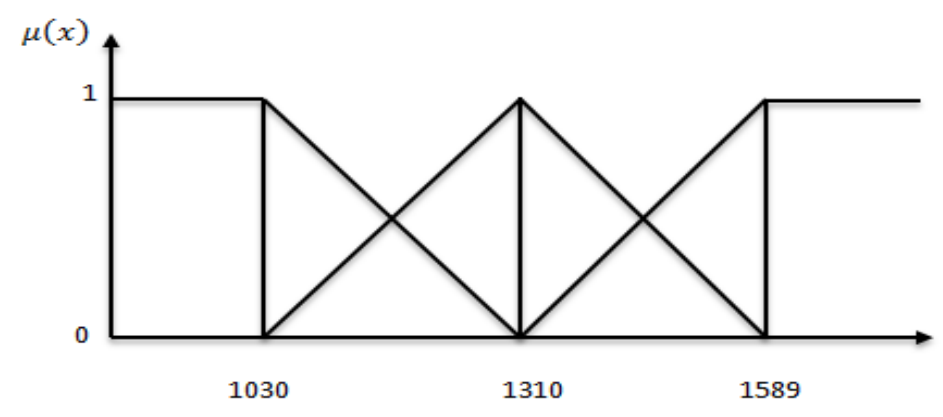

Gambar 1. Himpunan Fuzzy dari Variabel Permintaan

- Fungsi keanggotaan himpunan Fuzzy SEDIKIT, SEDANG, dan BANYAK dari variabel Persediaan

$$
\begin{aligned}
\mu[y] S E D I K I T & = \begin{cases}1, & y \leq 607 ; \\
\frac{750-x}{750-607}, & 607 \leq x \leq 750 ; \\
0, & x \geq 750 .\end{cases} \\
\mu[y] \text { SEDANG } & = \begin{cases}0, & y \leq 607 \text { atau } x \geq 894 ; \\
\frac{x-750}{750-607}, & 607 \leq x \leq 750 ; \\
\frac{894-x}{894-750}, & 750 \leq x \leq 894 .\end{cases} \\
\mu[y] B A N Y A K & = \begin{cases}0, & y \leq 750 ; \\
\frac{x-750}{894-750}, & 750 \leq x \leq 894 ; \\
1, & x \geq 894 .\end{cases}
\end{aligned}
$$

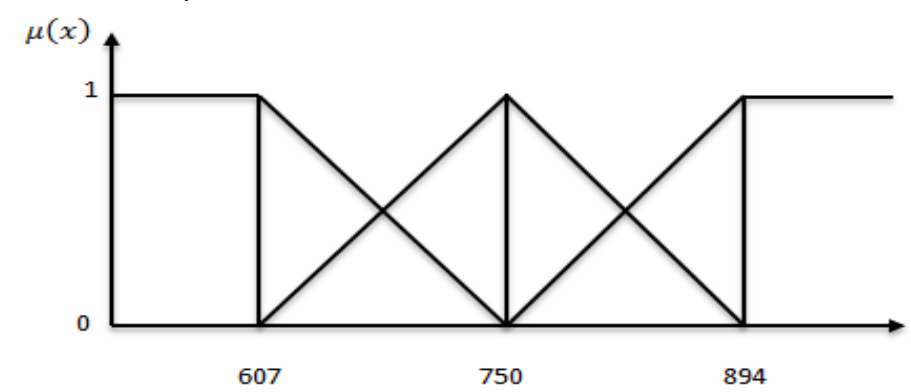

Gambar 2. Himpunan Fuzzy dari Variabel Persediaan

- Fungsi keanggotaan himpunan Fuzzy SEDIKIT, SEDANG, dan BANYAK dari variabel Produksi

$$
\begin{aligned}
& \mu[y] \text { SEDIKIT }= \begin{cases}1, & y \leq 1996 ; \\
\frac{2275-x}{2275-1996}, & 1996 \leq x \leq 2275 ; \\
0, & x \geq 750 .\end{cases} \\
& \mu[y] \text { SEDANG }= \begin{cases}0, & y \leq 1996 \text { atau } x \geq 2579 \\
\frac{x-2275}{2275-1996}, & 1996 \leq x \leq 2275 ; \\
\frac{2579-x}{2579-2275}, & 2275 \leq x \leq 2579\end{cases} \\
& \mu[y] \text { BANYAK }= \begin{cases}0, & y \leq 2579 \\
\frac{x-2257}{2579-2257}, & 2257 \leq x \leq 2579 \\
1, & x \geq 2579 .\end{cases}
\end{aligned}
$$




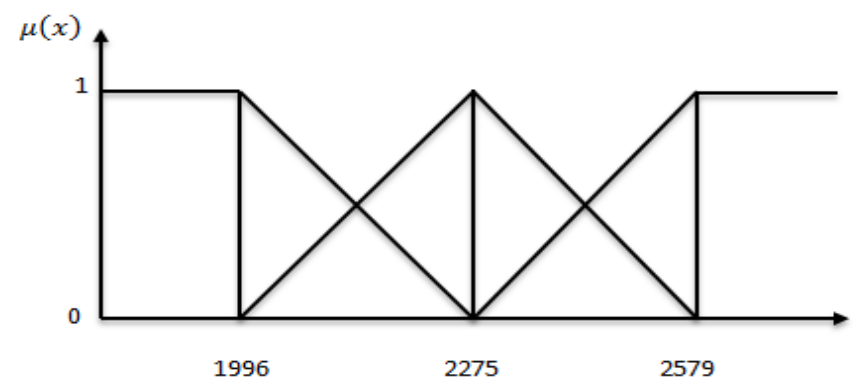

Gambar 3. Himpunan Fuzzy dari Variabe Produksi

\subsection{Implementasi Program}

Program yang dipakai dalam pembahasan ini adalah MATLAB yang bertujuan untuk membantu menghitung banyaknya produksi roti khususnya pada tahapan defuzzifikasi pada Pabrik Roti Sarinda berdasarkan data permintaan dan persediaan.

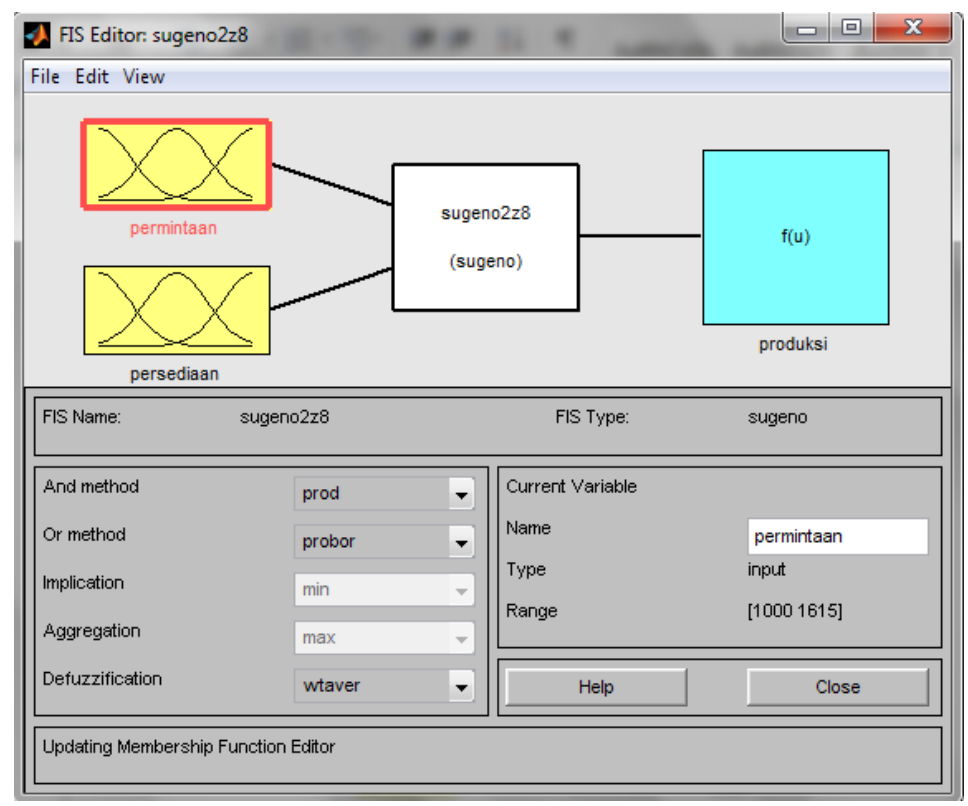

Gambar 4. Penerapan masalah ke dalam Aplikasi

Pada Gambar 4 ini adalah tahap pembentukan variabel input dan output. Dapat dilihat ada dua input yang berwarna kuning yaitu permintaan dan persediaan kemudiaan yang berwarna biru adalah output yaitu produksi. Tahap selanjutnya pembentukan himpunan Fuzzy dan fungsi keanggotaan. Pada Gambar 1 pilih input permintaan untuk dibuat fungsi keanggotaan yang lebih detail, yaitu untuk fungsi keanggotaan, KECIL, SEDANG dan BESAR range adalah [1000-1600] untuk fungsi keanggotaan KECIL tipe variabelnya adalah trapmf dengan parameternya [778 9751030 1310], SEDANG tipe variabelnya adalah trimf dengan parameternya [1030 1310 1589] sedangkan fungsi keanggotaan BANYAK tipe variabelnya trapmf dengan parameternya [1310 15891695 1796] hasilnya ditampilkan pada Gambar 2. 


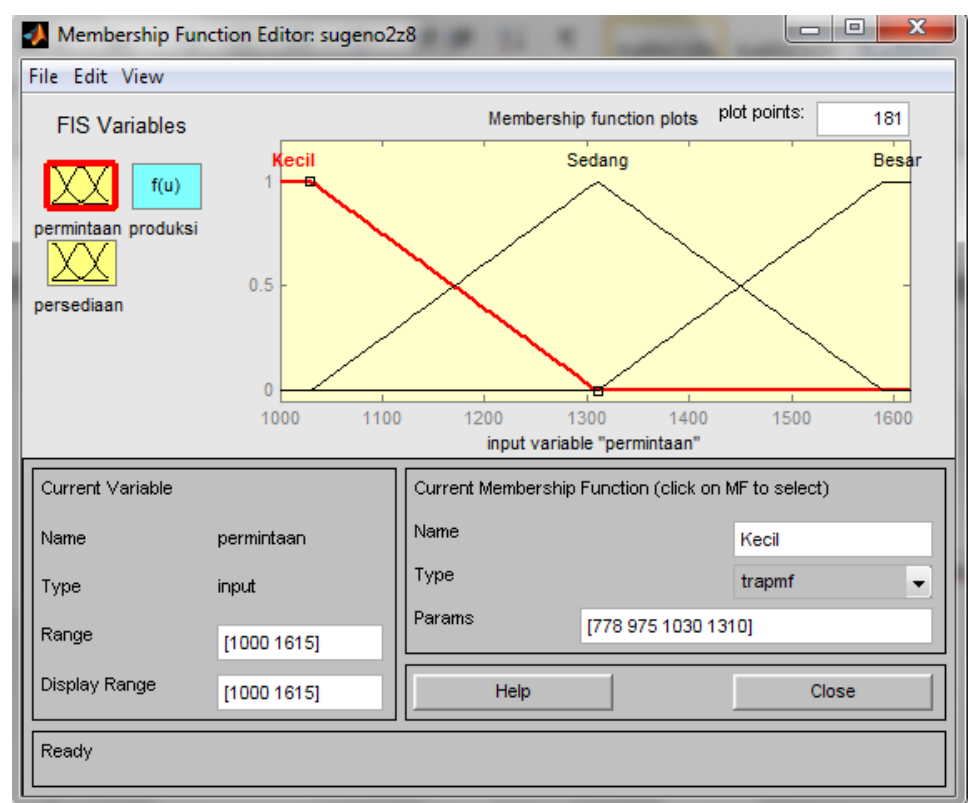

Gambar 5. Fungsi Keanggotaan Variabel Input Permintaan

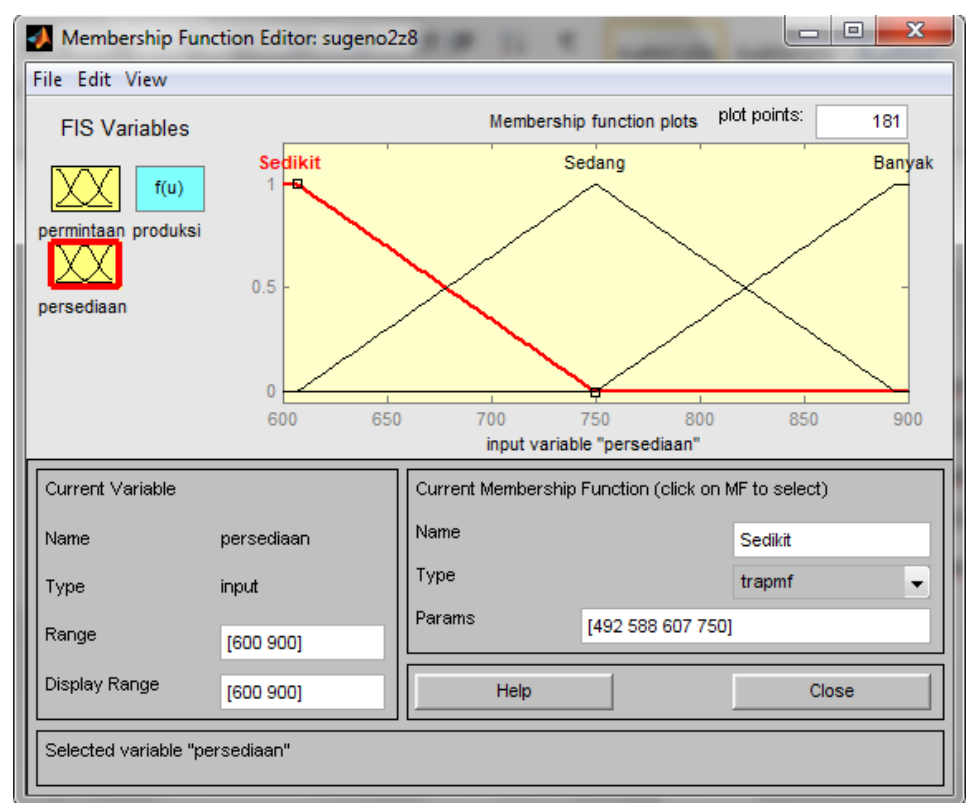

Gambar 6. Fungsi Keanggotaan Variabel Input Persediaan

Pada Gambar 5 di atas pula, dipilih input persediaan untuk dibuat fungsi keanggotaan yang lebih detail, yaitu untuk fungsi keanggotaan SEDIKIT, SEDANG dan BANYAK mempunyai range [600-900]. Untuk fungsi keangotaan SEDIKIT tipe variabelnya adalah trapmf dengan parameternya [492 588607 750], untuk fungsi keangotaan SEDANG tipe variabelnya adalah trimf dengan parameternya [607 750 894] sedangkan fungsi keanggotaan BANYAK tipe variabelnya adalah trapmf dengan parameternya [750 894912 1008] hasilnya ditampilkan pada Gambar 6.

Demikian pula untuk output produksi dari Gambar 1 di atas dipilih output produksi untuk dibuat fungsi keanggotaan lebih detail, yaitu untuk fungsi keanggotaan SEDIKIT, SEDANG dan BANYAK rangenya adalah [1950-2600]. Untuk fungsi keangotaan SEDIKIT, SEDANG dan BANYAK tipe variabelnya adalah constant dengan parameternya [1996], [2275] dan [2579]. 


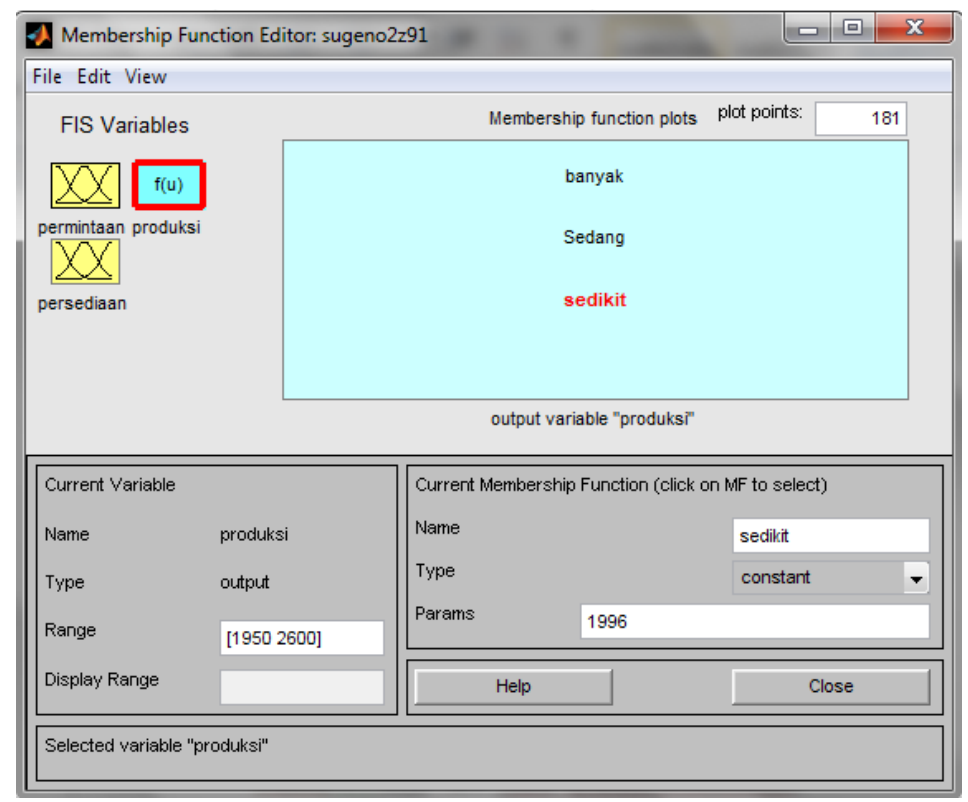

Gambar 7. Fungsi Keanggotaan Variabel Output Produksi

Dengan menyusun aturan Fuzzy seperti pada Tabel 4 ke dalam tollbox Matlab maka hasilnya adalah:

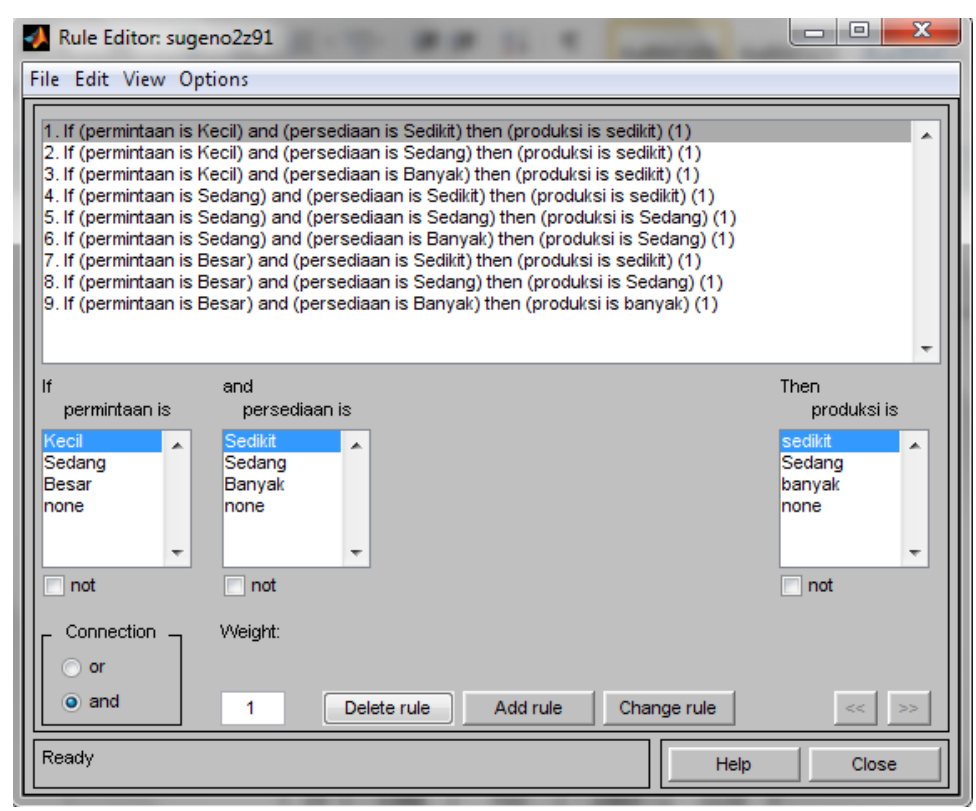

Gambar 8. Aturan Fuzzy berdasarkan Variabel Linguistik

Berdasarkan rule yang ada diperoleh rule view untuk simulasi hasil yang ingin diperoleh pada Gambar 9. 


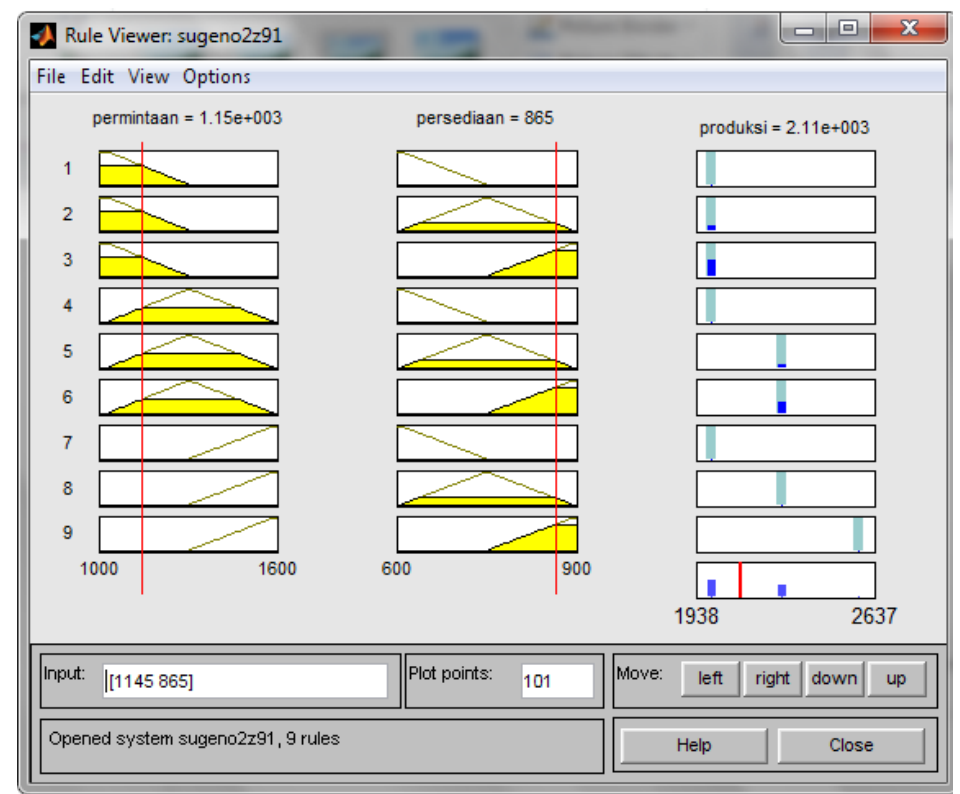

Gambar 9. Rule view (Hasil Optimasi/ Defuzzifikasi)

Pada Gambar 6 kita bisa mengoptimasi beberapa data permintaan dan jumlah persediaan yang ada maka kita akan mengetahui berapa jumlah produk yang harus diproduksi. Misalnya kita mengoptimasi input permintaan sebanyak 1415 dan input persediaan yang ada sebanyak 625 maka jumlah produk yang harus diproduksi oleh sistem pengambilan keputusan Sugeno ini adalah 2030 produk, hasil tampilannya terlihat pada Gambar 10.

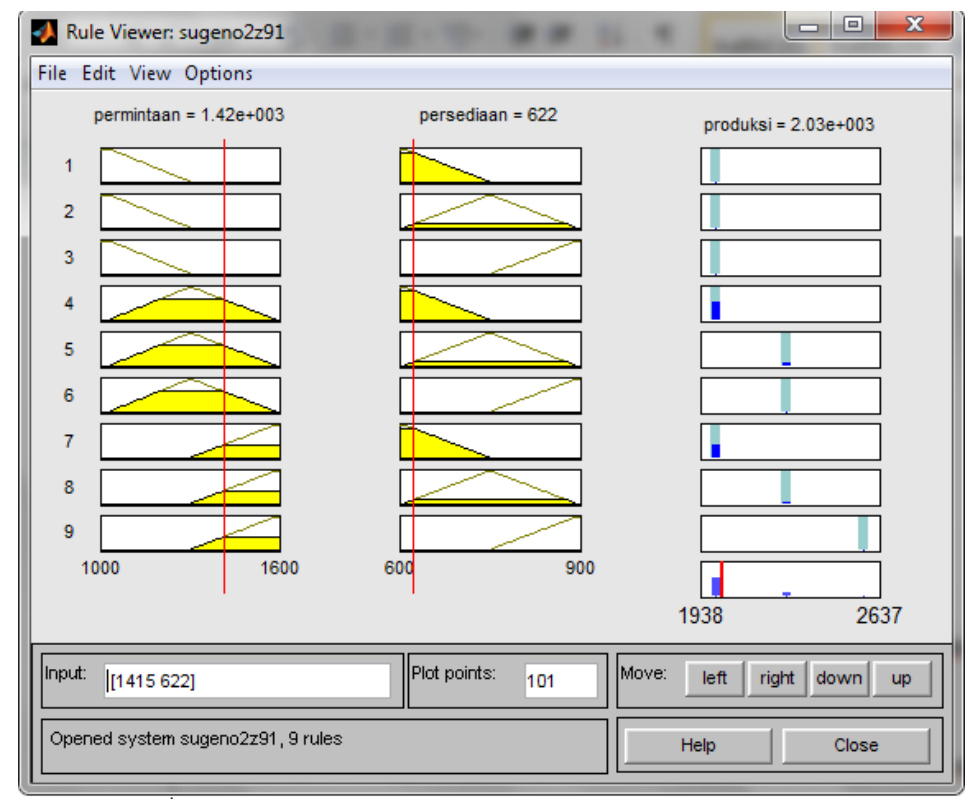

Gambar 10. Hasil Optimasi dengan Jumlah Permintaan 1415 dan Persediaan 622 
Tabel 5. Jumlah Produk yang Harus di Produksi Berdasarkan Input Permintaan dan Persediaan (Fuzzy sugeno)

\begin{tabular}{|c|c|c|c|c|c|}
\hline No & Tgl & Prm & Prs & Prd & Fu22y \\
\hline 1 & 2 & 1415 & 622 & 2400 & 2030 \\
\hline 2 & 4 & 1145 & 865 & 2210 & 2110 \\
\hline 3 & 5 & 1264 & 783 & 2118 & 2240 \\
\hline 4 & 6 & 1295 & 736 & 2098 & 2240 \\
\hline 5 & 7 & 1324 & 854 & 2565 & 2290 \\
\hline 6 & 8 & 1589 & 806 & 2579 & 2390 \\
\hline 7 & 9 & 1279 & 679 & 2282 & 2120 \\
\hline 8 & 11 & 1239 & 873 & 2339 & 2210 \\
\hline 9 & 12 & 1398 & 877 & 2541 & 2360 \\
\hline 10 & 13 & 1090 & $88 B$ & 1996 & 2060 \\
\hline 11 & 14 & 1064 & 894 & 2167 & 2030 \\
\hline 12 & 15 & 1384 & 722 & 2362 & 2220 \\
\hline 13 & 16 & 1315 & 766 & 2417 & 2280 \\
\hline 14 & 18 & 1355 & 607 & 2341 & 2000 \\
\hline 15 & 19 & 1156 & 730 & 2218 & 2110 \\
\hline 16 & 20 & 1241 & 680 & 2309 & 2110 \\
\hline 17 & 21 & 1570 & 653 & 2437 & 2090 \\
\hline 18 & 22 & 1297 & 629 & 2229 & 2040 \\
\hline 19 & 23 & 1366 & 697 & 2373 & 2170 \\
\hline 20 & 25 & 1185 & 728 & 2208 & 2130 \\
\hline 21 & 26 & 1089 & 736 & 2093 & 2050 \\
\hline 22 & 27 & 1519 & 618 & 2258 & 2020 \\
\hline 23 & 28 & 1030 & 616 & 2157 & 2000 \\
\hline 24 & 29 & 1376 & 662 & 2301 & 2030 \\
\hline 25 & 30 & 1555 & 863 & 2488 & 2490 \\
\hline
\end{tabular}

Dari hasil penerapan Logika Fuzzy (Sugeno) pada tollbox Matlab maka didapat hasil perbandingan penilaian logika Fuzzy (Sugeno) dengan produksi Pabrik Roti Sarinda Ambon, menggunakan persentase rata-rata atau Mean Percentage Error (MPE) dapat dilihat pada Tabel dibawah ini. 
Tabel 6. Perbandingan Penerapan Logika Fuzzy Metode Sugeno

\begin{tabular}{|c|c|c|c|c|c|}
\hline No & $\mathrm{Tg} \mid$ & $\begin{array}{c}Y_{t} \\
\text { (Prd) }\end{array}$ & $\begin{array}{c}\hat{q}_{\mathrm{t}} \\
\text { (Fuzzy) }\end{array}$ & Error & $\frac{\left(Y_{t}-\dot{Y}_{t}\right)}{Y_{t}} \times 100 \%$ \\
\hline 1 & 2 & 2400 & 2030 & 370 & 26.14841 \\
\hline 2 & 4 & 2210 & 2110 & 100 & 8.733624 \\
\hline 3 & 5 & 2118 & 2240 & 122 & 9.651899 \\
\hline 4 & 6 & 2098 & 2240 & 142 & 10.96525 \\
\hline 5 & 7 & 2565 & 2290 & 275 & 20.77039 \\
\hline 6 & 8 & 2579 & 2390 & 189 & 11.89427 \\
\hline 7 & 9 & 2282 & 2120 & 162 & 12.66615 \\
\hline 8 & 11 & 2339 & 2210 & 129 & 10.41162 \\
\hline 9 & 12 & 2541 & 2360 & 181 & 12.94707 \\
\hline 10 & 13 & 1996 & 2060 & 64 & 5.87156 \\
\hline 11 & 14 & 2167 & 2030 & 137 & 12.87594 \\
\hline 12 & 15 & 2362 & 2220 & 142 & 10.26012 \\
\hline 13 & 16 & 2417 & 2280 & 137 & 10.41825 \\
\hline 14 & 18 & 2341 & 2000 & 341 & 25.16605 \\
\hline 15 & 19 & 2218 & 2110 & 108 & 9.342561 \\
\hline 16 & 20 & 2309 & 2110 & 199 & 16.03546 \\
\hline 17 & 21 & 2437 & 2090 & 347 & 22.10191 \\
\hline 18 & 22 & 2229 & 2040 & 189 & 14.57209 \\
\hline 19 & 23 & 2373 & 2170 & 203 & 14.86091 \\
\hline 20 & 25 & 2208 & 2130 & 78 & 6.582278 \\
\hline 21 & 26 & 2093 & 2050 & 43 & 3.948577 \\
\hline 22 & 27 & 2258 & 2020 & 238 & 15.6682 \\
\hline 23 & 28 & 2157 & 2000 & 157 & 15.24272 \\
\hline 24 & 29 & 2301 & 2030 & 271 & 19.69477 \\
\hline 25 & 30 & 2488 & 2490 & 2 & 0.128617 \\
\hline
\end{tabular}

Tabel 7. Perhitungan MPE Metode Sugeno

\begin{tabular}{|c|}
\hline$\sum_{t=1}^{n}\left|\frac{\left(\gamma_{t}-\gamma_{t}\right)}{\gamma_{t}} x 100 \%\right|=326.9587$ \\
\hline$\left(\frac{\sum_{t=:}^{n} \mid \frac{\left.\gamma_{t}-\gamma_{t}\right]_{1}}{\gamma_{t}} \times 100 \% 6}{n}\right)=13.07835$ \\
\hline $100-13.1916=86.92165$
\end{tabular}

Sehingga didapat hasil perhitungan rata-rata persentase kesalahan dari Logika Fuzzy Metode Sugeno yang digunakan adalah 13.07835 sedangkan tingkat kebenaran dari hasil perhitungan tersebut adalah 86.92165 maka dapat disimpulkan bahwa hasil dari perhitungan Logika Fuzzy Metode Sugeno yang digunakan pada sistem ini dapat digunakan untuk prediksi jumlah produksi pada Pabrik Roti Sarinda Ambon. 


\section{Kesimpulan}

Berdasarkan rumusan masalah, hasil penelitian dan pembahasan mengenai penentuan jumlah produksi roti berdasarkan jumlah persediaan dan permintaan dapat diambil beberapa kesimpulan, yaitu :

a. Untuk menentukan jumlah produksi dapat memasukan nilai pada kolom input pada Gambar 10 sesuai dengan data yang ada atau dengan data yang lain yang masih berada pada nilai domain fungsi.

b. Dari hasil perbandingan, Logika Fuzzy Sugeno dapat dipakai sebagai alat peramalan dalam menentukan jumlah produksi berdasarkan jumlah permintaan dan persediaan Pabrik Roti Sarinda Ambon dengan nilai kebenaran mencapai $86.92 \%$.

\section{Daftar Pustaka}

[1] Zimmermann, Fuzzy Set Theory and Its Application, Massachusetts: Kluwer Academic Publisher, 1991.

[2] L. Fauset, Fundamentals of Neural Networks, New Jersey: Prentice Hall, 1994.

[3] S. Kusumadewi, Membangun Jaringan Syaraf Tiruan Menggunakan Matlab dan Excel Link, Yogyakarta: Graha Ilmu, 2004.

[4] S. Kusumadewi, Analisis dan Desain Sistem Fuzzy Menggunakan Tool Box Matlab, Yogyakarta: Graha Ilmu, 2002.

[5] S. Kusumadewi and H. Purnomo, Aplikasi Logika Fuzzy untuk Pendukung Keputusan, Yogyakarta: Graha Ilmu, 2004.

[6] M. Arhami, Konsep Dasar Sistem Pakar Jilid 1, Yogyakarta: Penerbit Andi, 2005.

[7] Sukandy, M. Dwi, T. Basuki and S. Puspasari, Penerapan Metode Fuzzy Mamdani untuk Memprediksi Jumlah Produksi Minyak Sawit Berdasarkan Data Persediaan dan Jumlah Permintaan (Studi Kasus PT Perkebunan Mitra Ogan Baturaja), Baturaja, 2014.

[8] M. Yunus and W. Atim, "Penerapan Logika Fuzzy (Mamdani) untuk Menentukan Jumlah Produksi Roti Berdasarkan Data Persediaan dan Jumlah Produksi Minyak Sawit Berdasarkan Data Persediaan dan Jumlah Permintaan (Studi Kasus: PT. Bosinda Cahaya Anugrah),"Jurnal Teknoinfo, vol. 10, no. 1, pp. 1-8, 2014. 